\title{
CFD aided design and experimental validation of an innovative air assisted pure water jet cutting system
}

\author{
M. Annoni, F. Arleo, C. Malmassari \\ Dipartimento di Meccanica, Politecnico di Milano, via La Masa 1 - 20156, Milano (Italy)
}

\begin{abstract}
Water jet cutting has always been a promising technology because of its extreme simplicity and flexibility, even if it often suffers a lack of control on its process parameters, especially if compared to technologies such as laser cutting or electro-discharge machining. Recent studies have showed how the presence of water inside the orifice causes disturbances and instabilities which systematically affect the jet structure, both during the jet formation and the cutting process. These disturbances can be neglected in industrial applications, but they can play a relevant role in case of high-precision water jet machining. The aim of the research presented in this paper is to develop an innovative system able to modify the orifice flow field by means of a simple modification of the standard cutting head geometry; the system allows the controlled injection of air inside the primary orifice to prevent the jet instabilities and to adapt the level of jet coherence to the specific machining operation. The fluid dynamics aspects of the outflow process are investigated by means of a 3D numerical simulation with the Ansys Fluent CFD solver, while considerable experimental efforts are provided in order to validate the numerical model and finally evaluate the system performances on real case studies.
\end{abstract}

Keywords: pure water jet, jet stability, jet coherence, air injection, jet structure control, CFD simulation.

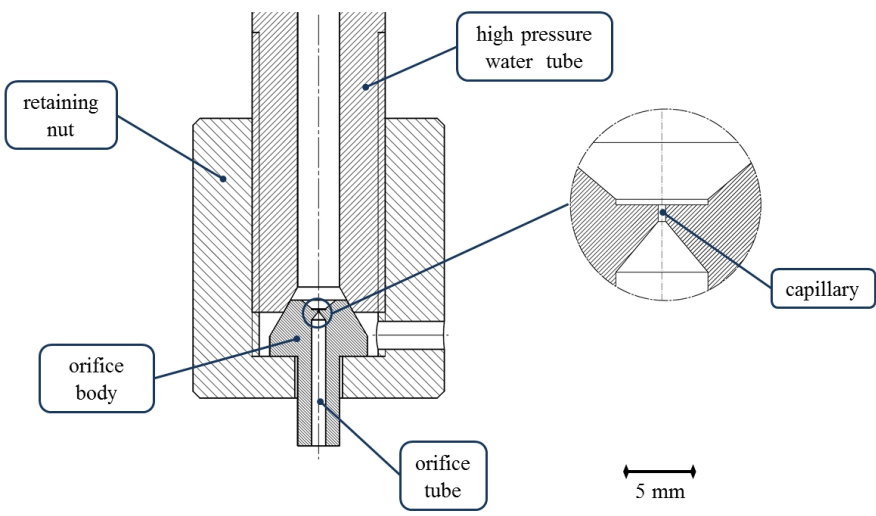

Figure 1: Standard WJ cutting head components

\section{Introduction}

The improvement of a manufacturing process goes along with the coherent knowledge improvement of all the involved physical phenomena and influencing factors: from this point of view, it has to be considered that the Pure Water Jet (PWJ) is inevitably the core of the Abrasive Water Jet (AWJ) as well, since the abrasive particles addition takes place downstream the main water jet creation, which is basically the same for both PWJ and AWJ.

It comes clear that the study of the outflowing process from the primary orifice, along with a deeper understanding of the fluid dynamic phenomena and the possibility to control them are all crucial factors for the water jet cutting technology improvement as a whole.

Monno et al. (2007) underlined that the basic principle of PWJ cutting technology is the maximization of the specific energy per unit area. The water jet structure produced by an orifice turns out to have a great importance on the cutting efficiency of the produced jet and, as a consequence, on the kerf quality; many efforts have been made in order to gain knowledge on these phenomena both theoretically and experimentally.

The first important contributions on these topics were given by Ohnesorge (1936), who presented a classification of flow regimes for rounded-edge nozzles working at different Reynolds and Weber numbers. The former work was integrated by Lin and Reitz (1998) and Lefebvre (1989), who highlighted the different breakup regions of a fluid jet ("dripping", "Rayleight", "first" and "second wind induced" and "atomization").

Moreover, Lichtarowicz et al. (1965) collected a comprehensive experimental summary of the orifice discharge coefficients with length to diameter ratios up to 10 working at Re up to $10^{5}$. According with Annoni and Monno (2006), rounded-edge orifices working with the typical Re numbers of WJ applications would produce a completely atomized jet, which is not in accordance with the jet structure that can be actually observed during machining operations.

Dealing with this aspect, the numerical and experimental studies by Vahedi Tafreshi and Pourdeyhimi (2003) showed the importance of nozzle geometry on the creation of a coherent and stable jet. In fact, using sharp-edged orifices together with high working pressures, it is possible to reach and mantain the 
"hydraulic flip" condition, which allows the jet to remain detached from the capillary walls thanks to its extremely high momentum.

Schweitzer (1937) stated that a jet in a stable hydraulic flip condition is characterized by a constricted structure, which looks glassy and transparent like a laminar flow in spite of its very high Re values.

Furthermore, another important feature of the "flipped" jet is the breakup length, which is significantly longer if compared to a non-constricted jet in the same working conditions, as shown by Anantharamaiah et al. (2006).

These analysis were integrated by Arleo (2010) with an analytical study of the water jet outflow process, which confirmed that sharp-edged orifices supplied by the typical pressure values used in WJ cutting applications work in a stable condition of hydraulic flip.

Finally, Jou (2000) applied linear stability theory to theoretically analyze the water jet stability with respect to the upstream pressure fluctuations, pointing out that high-freauency waves must b at developing flow to obtain a nat taking jet.

b. at developing al background, th 1 work aims to develop an innovative cutting head which takes advantage of the air injection inside the primary orifice in order to guarantee the hydraulic flip condition and to adapt the jet structure to the specific machin.

The desi_ studied by iveness of the investigated solu validated by has been tested througn numerical CFD simulations and v tioun experir relevance ystem prototype.

The importaniee of the controlled jet structure on the eut suifface quality has been highlighted by some preliminary cutting test on foams and textile materials which showed that such a system can improve the cutting quality. Moreover the obtained results seem promising for a further integration of an air assisted system in an AWJ cutting head, eventually giving opportunity to high performance water jet cutting applications.

\section{Jet stability and coherence}

The hydraulic flip condition is the optimal outflow regime for PWJ machining purposes because, if not altered, it guarantees the best performances in terms of jet coherence and stability.

At this point, it is necessary to introduce the definitions of jet coherence and jet stability, which will be used throughout this study to describe the main features of the outflow process.

The jet coherence refers to the morphological characteristics of the liquid structure: high coherence indicates a jet with a thin and glassy appearance, whose fluid particles are not detectable but joined together in a compact flow. This property is fundamental because it allows the jet diameter, and the kerf width as a consequence, to be close to the capillary diameter, which is always very small (from 0.05 to $0.15 \mathrm{~mm}$ in common PWJ applications) in order to maximize the specific energy per unit area available for the cutting process.

The jet stability instead is defined as the capability of the jet structure to reach and maintain its level of coherence during the outflow process. This characteristic is important because it is directly related to the cutting quality dispersion in terms of kerf width and surface roughness.

Summarizing, it can be inferred that stability refers to the jet behavior in time, while coherence deals with its behavior in space. For instance, a jet showing a noticeable but steady divergence has a poor coherence but high stability, while a pulsating jet showing high breakup lengths turns out to be highly coherent but not stable.

In accordance to this, the jet instability could be defined as the variation of the jet coherence in time, which usually results in temporary losses of the hydraulic flip condition.

When an outflow instability takes place, the jet gets wider in a spray-like manner before returning to a stable and constricted condition after some whiles, as shown in Figure 2.

As reported by Arleo (2010), this phenomenon is characterized by short durations (about $1 \mathrm{~ms}$ ) and random frequency, and it seems not related to any systematic irregularities of the WJ system, such as upstream pressure fluctuations or orifice wear.

$d_{\mathrm{o}}=0.08 \mathrm{~mm} \quad p_{\text {up }}=160 \mathrm{MPa} \quad v_{\mathrm{th}}=566 \mathrm{~m} / \mathrm{s}$ Sampling frequency $=20000 \mathrm{~Hz}$

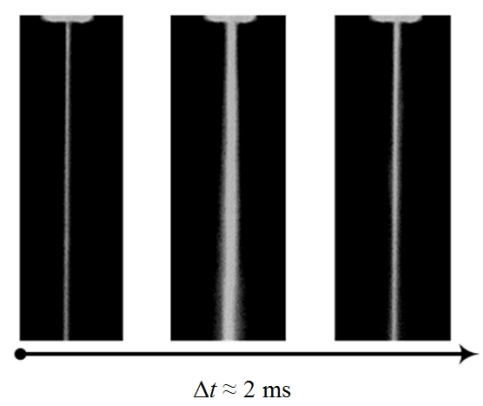

Figure 2: Instabilities of a PWJ recorded with a High Speed Camera (HSC) Arleo (2010).

In his previous works, Arleo (2010) inferred that the main cause of the aforementioned instabilities is the presence of droplets inside the orifice tube. Water filling the orifice while the jet is off, condensed humidity and jet breakup are the main sources of droplets formation in working conditions.

In fact, numerical simulations by Arleo et al. (2011) showed that droplets that are not completely flushed out, recirculate inside the orifice tube dragged by the air velocity field surrounding the jet, eventually reaching the top capillary where they cause the local loss of the hydraulic flip condition and so the inception of instabilities, as shown in Figure 3.

The aim of the present study is to inject air inside the orifice to modify the orifice flow field preventing these droplets to move towards the capillary, enhancing the jet stability (see Section 3).

Moreover, the controlled air injection can modifiy the jet coherence level, as it will be explained in Sections 5 and 7, allowing to adjust it to the specific cutting application.

The influence of a gas cross-flow on the coherence of a liquid jet is well known in literature and supported by several studies and patents by Hashish (24 Dec 2009, 05 Apr 2005). Anyway, no studies can be found in literature about the application of such a solution to PWJ machining processes in order to ac- 

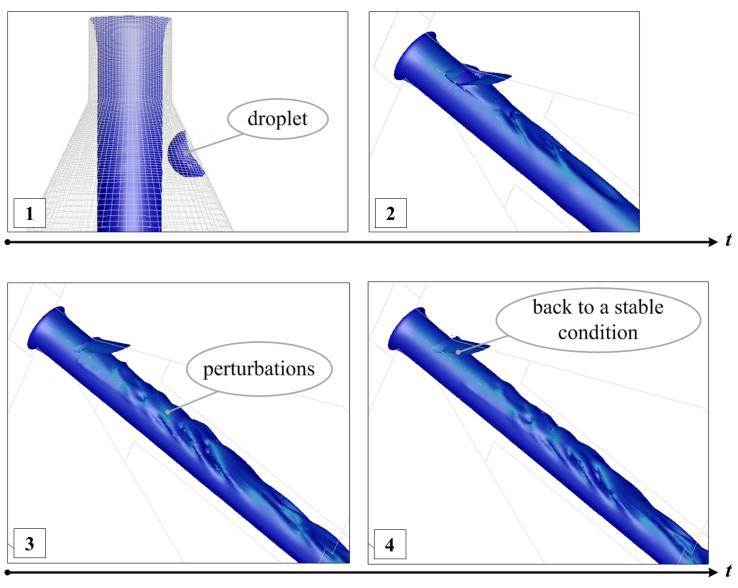

Figure 3: Inception of a jet instability caused by a droplet perturbation Arleo et al. (2011).

tively control the water jet structure and coherence or enhance the jet stability; nevertheless, no documentation can be found on the effects of the PWJ jet coherence on the machined part kerf quality.

The present study investigates this opportunity by means of 3D Computational Fluid Dynamics (CFD) simulations validated by a proper experimentation. Real cutting tests finally demonstrate the effectiveness of the proposed innovation.

\section{Numerical model}

Due to the high velocities reached by the jet (up to $800 \mathrm{~m} / \mathrm{s}$ and above), its rapid dynamics and the small characteristic dimensions of the PWJ cutting head, quantitatively correct measurements and empirical approaches are often very difficult. For this reason, CFD analysis is increasingly used as a viable way to study the process physics, especially in AWJ applications. For instance, in the recent literature Prisco and D'Onofrio (2009) and Basha et al. (in press) investigated on the fluid dynamics inside an AWJ cutting head with a two-phases 3D model, Liu et al. (2004) tracked the jet velocity profile distribution at different distances from the nozzle exit by means of a 2D model of an AWJ nozzle and Wang and Wang (2010) set up a threephases $2 \mathrm{D}$ numerical model in order to predict the abrasive particles position and velocity across the jet section downstream the nozzle exit.

In the present work instead, numerical simulations have been chosen as a design tool to improve the complex unsteady turbulent two-phase 3D micro flow inside a PWJ orifice, with the aim to enhance the jet stability through a modification of its geometry.

The modification of the orifice flow field has been achieved by connecting the orifice tube with the outside ambient through a hole (Figure 4). Compatibly with the hole machinability (see Section 5), this feature has been designed considering the simplest possible configuration, that is a hole machined with its axis perpendicular to the orifice tube axis. Furthermore, the hole diameter has been designed as the smallest feasible $(0.2 \mathrm{~mm})$ so as to have a localized effect and not to excessively alter the orifice inner geometry.

\subsection{Numerical settings}

A 3D numerical model has been set up in Fluent ${ }^{\circledR}$ with the aim to study the effects of the proposed solution on the inner fluid flow. Since the geometrical domain and the perturbation dynamics are non-symmetrical, a 3D model is necessary to correctly represent the fluid flow; the simulation domain is presented in Figure 4.
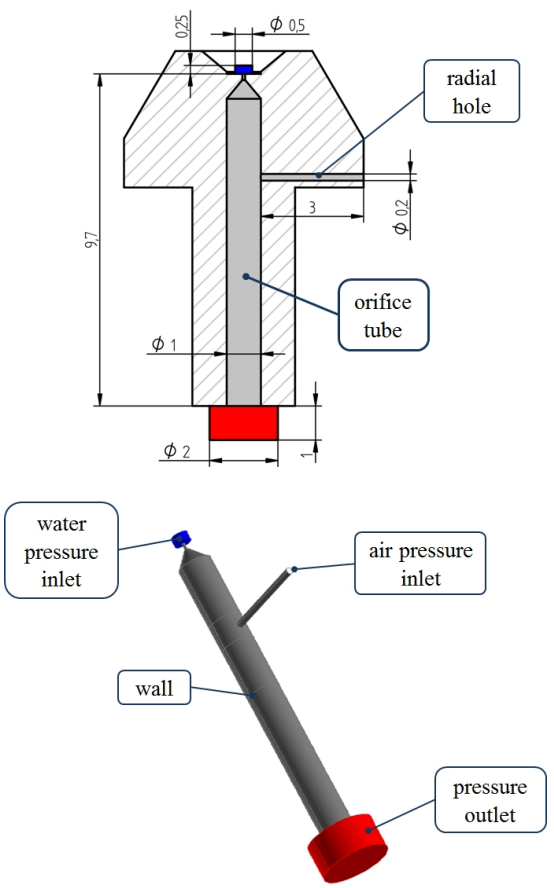

Figure 4: Scheme of the studied part (above) and extraction of the numerical 3D domain with the applied boundary conditions according to Fluent ${ }^{\circledR}$ nomenclature (below).

According to Fluent 12.0 Theory Guide by Ansys (2009a), for the present study purposes, the best way to simulate the mechanism of a water jet discharging in air is to set up a timedependent multiphase turbulent flow model with the addition of surface tension.

Volume Of Fluid (VOF) is used as multiphase model since it is particularly suitable to track the interface between two nonmiscible fluid phases (water and air), which are considered as incompressible in the present simulation. Surface tension is added as well for a correct evaluation of all the forces acting on the jet surface.

The rest of the settings have been select to obtain the best results in terms of simulation convergence and accuracy, as suggested in Fluent 12.0 User's Guide by Ansys (2009b).

A comprehensive model settings summary is reported in Table 1 .

In addition, since the resolution of the VOF surface tracking is strongly dependent on the mesh resolution, a mesh refinement has been performed in the interested areas (i.e. the orifice capillary region and the jet surrounding) in order to find the best compromise between results accuracy and computational effort. 


\begin{tabular}{ll}
\hline Model settings & \\
\hline $\begin{array}{l}\text { multiphase model } \\
\text { VOF scheme } \\
\text { time dependence } \\
\text { viscous model } \\
\text { turbulence model } \\
\text { body force } \\
\text { surface tension }\end{array}$ & $\begin{array}{l}\text { explicit } \\
\text { unsteady } \\
\text { turbulent } \\
\kappa \text { - } \epsilon \text { realizable }\end{array}$ \\
$\begin{array}{l}\text { Numerical settings } \\
\text { Pressure-velocity coupling }\end{array}$ & $0.0712 \mathrm{~N} / \mathrm{m}$ \\
$\begin{array}{l}\text { Spatial discretization } \\
\text { pressure } \\
\text { momentum }\end{array}$ & $\begin{array}{l}\text { PISO Scheme } \\
\text { volume fraction } \\
\text { turbulent kinetic energy }(\kappa)\end{array}$ \\
turbulent dissipation rate $(\epsilon)$ & $\begin{array}{l}2^{\text {nd }} \text { order } \\
2^{\text {nd }} \text { order }\end{array}$ \\
\hline
\end{tabular}

Table 1: Summary of the applied numerical settings.

\subsection{Boundary conditions}

Table 2 summarizes all the Boundary Conditions (BCs) while Figure 4 shows the subdomains where each boundary condition has been applied.

The water upstream pressure $p_{\text {up }}$ is set to $200 \mathrm{MPa}$ which is a typical working pressure value for PWJ applications, while atmospheric pressure is applied along the outside boundary, as it is also confirmed by Arleo (2010) trough experimental pressure acquisitions at the very exit of the orifice tube.

The no slip shear condition is set as a wall BC, which means that the fluid in contact with the domain surface has got null velocity. Also the water-air contact angle is introduced to the model, being set to an experimental value corresponding to water drops surrounded by air on a steel substrate as reported by First Ten Ångstroms (2003).

Regarding the air pressure inlet $\mathrm{BC}$, three different conditions have been simulated:

$\mathbf{1}^{\text {st }}$ simulation: $p_{\text {air,1 }}$ set to atmospheric pressure. This condition simulates the configuration where the orifice inner tube is simply connected with the outside ambient by the hole. Air is naturally sucked inside by the Venturi effect created by the flowing water jet inducing vacuum pressure inside the orifice tube;

$2^{\text {nd }}$ simulation: $p_{\text {air,2 }}$ set to $0.3 \mathrm{MPa}$. This condition simulates a compressed air intake from the outside. The pressure drop is increased, forcing the air to enter the orifice tube with higher velocity;

$3^{\text {rd }}$ simulation: the air inlet is kept closed by applying a wall condition. This configuration is useful for the model validation as it will be explained in Section 6.

\section{Numerical results}

The numerical analysis gives useful clues about the way how to set up the experimental system, which will be presented in Section 5.

\begin{tabular}{|c|c|c|c|}
\hline \multicolumn{4}{|l|}{ Boundary conditions } \\
\hline water pressure inlet & \multicolumn{3}{|l|}{$p_{\text {up }}=200 \mathrm{MPa}$} \\
\hline pressure outlet & \multicolumn{3}{|c|}{$p_{\text {down }}=101325 \mathrm{~Pa}$} \\
\hline wall & \multicolumn{2}{|c|}{$\begin{array}{l}\text { shear condition } \\
\text { water-air contact angle }\end{array}$} & $\begin{array}{l}\text { no slip } \\
76^{\circ}\end{array}$ \\
\hline air pressure inlet & $\begin{array}{l}1^{\text {st }} \text { simulation } \\
2^{\text {nd }} \text { simulation } \\
3^{\text {rd }} \text { simulation }\end{array}$ & $\begin{array}{l}p_{\text {air,1 }} \\
p_{\text {air,2 }} \\
\text { wall }\end{array}$ & $\begin{array}{l}=101325 \mathrm{~Pa} \\
=0.3 \mathrm{MPa}\end{array}$ \\
\hline
\end{tabular}

Results from the $1^{\text {st }}$ simulation (Figures 5 and 6) show that the air flux generated by the natural suction has not energy enough to adequately alter the inner air velocity field nor protect the capillary from any droplet moving upwards and possibly causing jet instabilities. In fact, as shown in Figure 5, there are still some pathlines going from the bottom towards the upper part of the orifice tube.

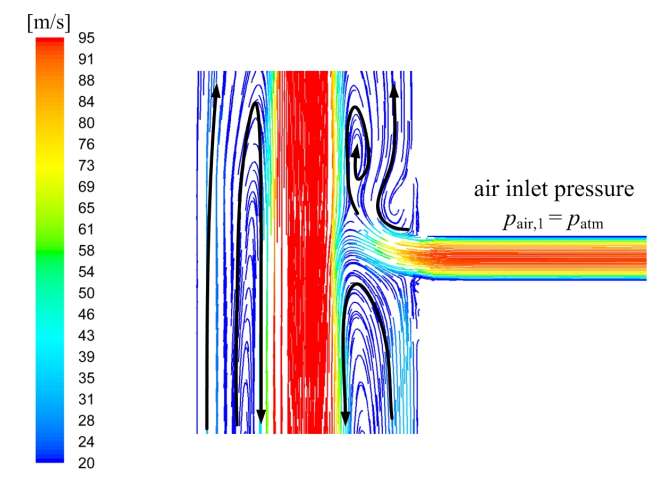

Figure 5: Zoom on the pathlines coloured by velocity contours (in $\mathrm{m} / \mathrm{s}$ ) in the air inlet region ( $1^{\text {st }}$ simulation)

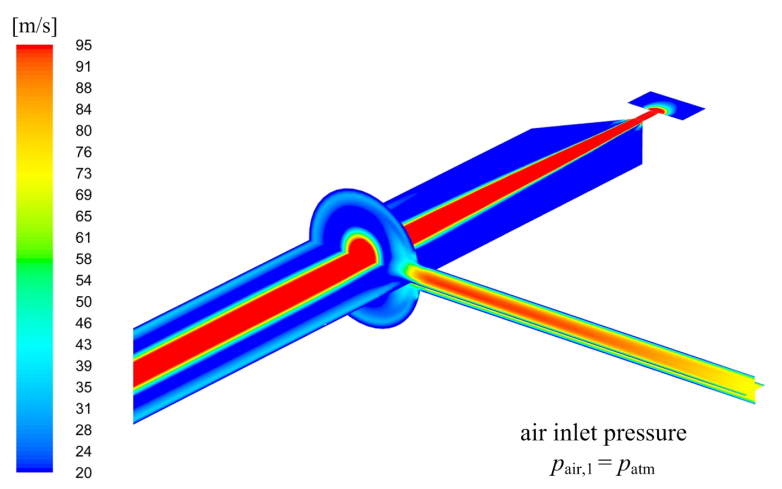

Figure 6: $3 \mathrm{D}$ velocity contour plot (in $\mathrm{m} / \mathrm{s})\left(1^{\text {st }}\right.$ simulation).

On the contrary, the analysis of the $2^{\text {nd }}$ simulation (Figures 7 and 8) shows that the radial high-velocity air flux effectively splits the flow field surrounding the water jet. Figure 7 shows how a big vortex creates in the air inlet region, acting as a protection for the capillary against any droplet or particle going upwards: the complete decoupling of the air flow field is achieved, 
separating the capillary region from the air inlet downstream region, finally preserving the hydraulic flip condition and the jet stability in time. These CFD results are the evidence of the effectiveness of the proposed solution.

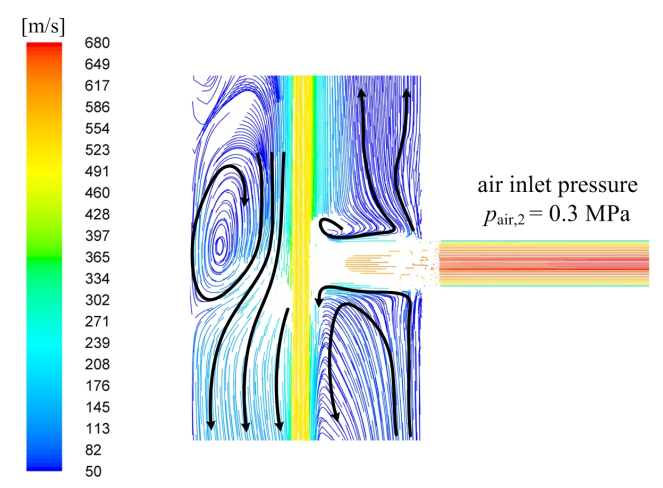

Figure 7: Zoom on the pathlines coloured by velocity contours (in $\mathrm{m} / \mathrm{s}$ ) in the air inlet region $\left(2^{2 \text { nd }}\right.$ simulation).

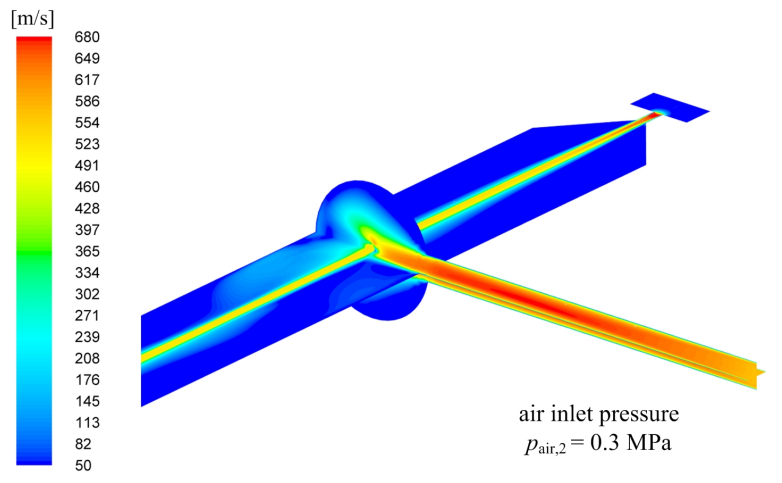

Figure 8: 3D velocity contour plot (in $\mathrm{m} / \mathrm{s})\left(2^{2 \text { nd }}\right.$ simulation).

As a conclusion of the presented CFD analysis, it is possible to infer that it is necessary to design a cutting head able to blow compressed air inside the orifice tube in order to achieve the desired effect on the flow field to protect the capillary and enhance the jet stability.

Nevertheless, the high velocity radial air flux impacting the main water jet can play also a role on the jet coherence since simulations show how it can locally perturb the jet surface acting on jet coherence and breakup length (Figure 9). More specifically, the higher the air pressure, the higher the disturbances and divergence and the lower the breakup length.

\section{The innovative $P W J$ cutting system}

The controlled intake of compressed air inside the orifice tube, whose effectiveness has been proved by CFD simulations (Section 4), can be obtained through a modification of both the orifice and its retaining flange. A section of the proposed airassisted PWJ system is presented in Figure 10.

A radial hole with a diameter of $0.2 \mathrm{~mm}$ is drilled in a standard orifice (see also Figure 4 ) by means of Electro Discharge Machining (EDM). A small diameter is selected to act locally

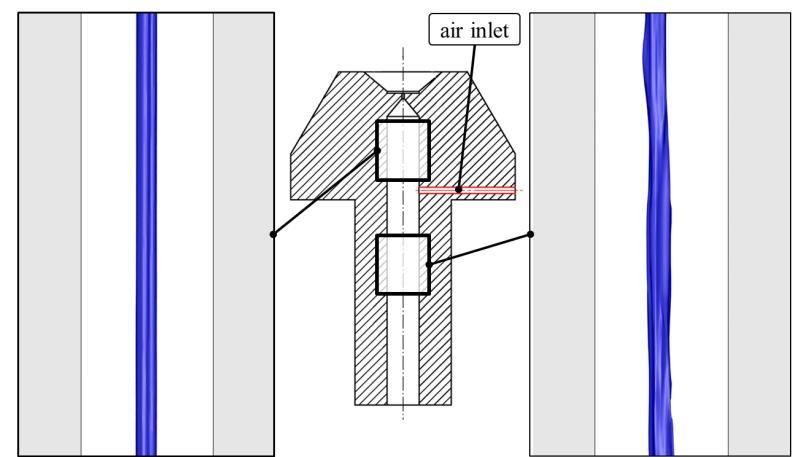

Figure 9: Jet-air interface before (left) and after (right) the air pressure inlet $\left(2^{\text {nd }}\right.$ simulation)

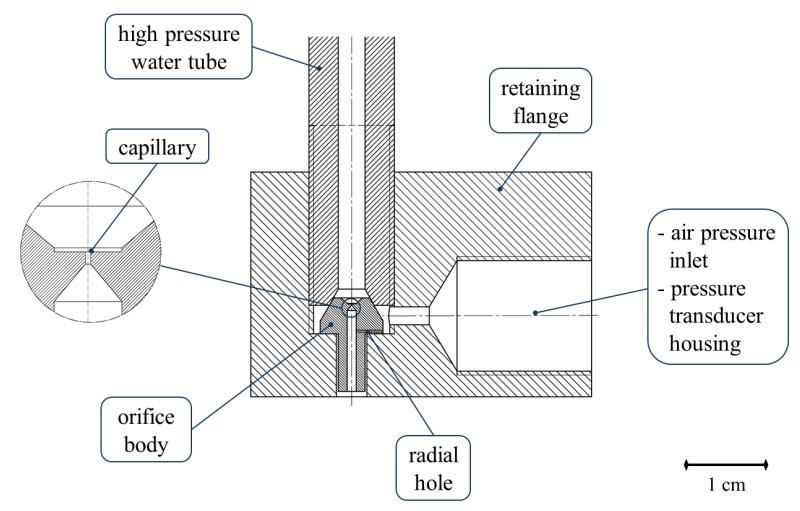

Figure 10: Cross-section of the innovative air assisted PWJ cutting head.

without excessively alter the inner geometry, while the location where the hole is drilled is due to machinability constraints. Through this hole, the orifice inner tube is linked first to the annulus surrounding the orifice body and then to the outside ambient through a threaded hole (Figure 10).

The latter threaded connection can be used as a plug-in port for the connection either with an external pressurized air feeding system control (see Section 5.1) or with a pressure transducer for process monitoring purposes (see Section 5.2).

\subsection{Pressurized air feeding configuration}

An external pressurized air feeding system is plugged to the threaded hole in this configuration allowing the system to be actively used to control the intake of air inside the orifice tube, as previously explained. Experimental trials show that the simulations results are coherent with reality: supplying sufficiently pressurized air ( $>0.3 \mathrm{MPa})$ is useful to stabilize the jet preventing any disturbance to reach the capillary and cause instability. Figure 11 qualitatively shows the influence of the air inlet pressure on the jet coherence and structure, highlighting how a sensible reduction of the breakup length and also a slightly spreading jet divergence is produced by progressively increasing the air pressure.

As mentioned in Section 4, this is due to the fact that a higher air inlet pressure produces perturbations on the jet surface downstream the air inlet region (Figure 9), making the jet 


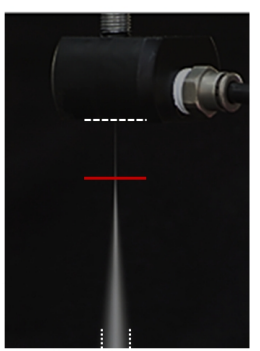

air pressure: $0.1 \mathrm{MPa}$

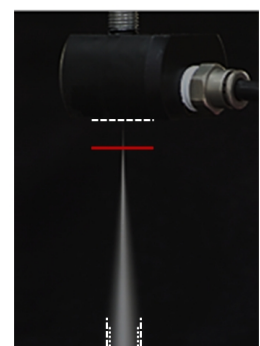

air pressure: $0.4 \mathrm{MPa}$

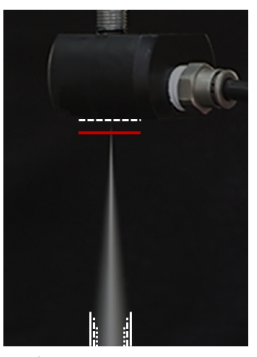

air pressure: $0.7 \mathrm{MPa}$
Figure 11: Influence of the air inlet pressure on the downstream jet structure

more sensible to the surrounding air friction and so more likely to earlier lose its coherence.

Concluding, it is possible to infer that a controlled air intake has a positive influence on the jet stabilization in time and it seems capable to control its coherence level in space. A deeper characterization of the system behavior is needed, as it will be pointed out in the following.

\subsection{Pressure monitoring}

A pressure transducer is connected to the threaded hole in order to monitor the vacuum pressure inside the orifice tube in this configuration: in this case, the system is passively used to detect any problems during machining operations, such as excessive orifice wear or orifice failure, which produce a modification of the pressure field inside the orifice tube. Figure 12 shows a possible monitoring configuration, with a pressure transducer connected to the retaining flange of the proposed Air Assisted Pure Water Jet (AAPWJ) system.

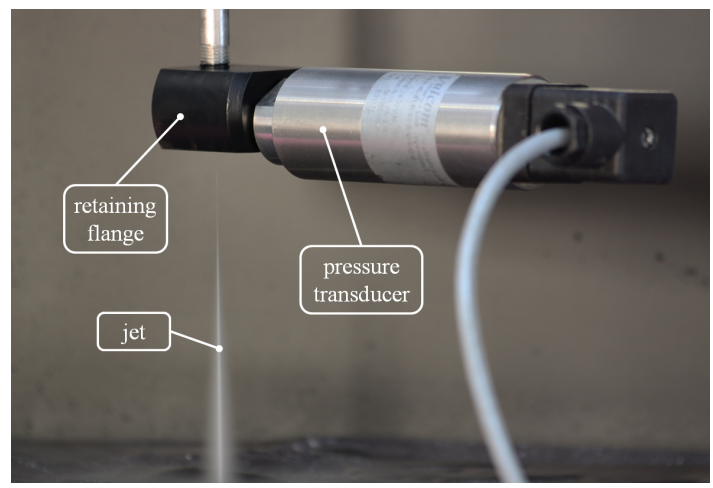

Figure 12: Pressure monitoring with a transducer connected to the jet retaining flange threaded hole.

Preliminary experiments showed promising results, especially in the detection of a broken orifice condition, which eventually produces a significant change in the pressure value if compared to standard working conditions.

A deeper characterization and screening of all the possible detectable failures will be performed in the future.

\section{Validation}

Experimental validation of numerical results is an essential step to evaluate the reliability and the effectiveness of the developed CFD model.

The setup and the carrying out of validating experiments is always challenging in WJ applications because of the physical domain small length scales (in the order of a millimeter or less) and the extremely high velocity scales (from 500 up to $900 \mathrm{~m} / \mathrm{s}$ ), making dynamic measurements of the outflow process and its behaviour almost impossible.

Despite of this fact, different validation results are presented in this section: besides the jet velocity comparison with the theoretical Bernoulli value, which is a standard validation procedure in literature, the jet real velocity ouside the orifice has been measured by means of Laser Doppler Velocimetry (LDV) system in order to prove the standard functionality of the modified orifice.

Furthermore, the orifice radial hole allowed to acquire the pressure signal inside the orifice tube very close to the capillary region. This experiment represents an absolute innovation for the WJ technology because it can be used for monitoring purposes (as explained in Section 5.2) but also as a useful method for CFD validation, never found in the available WJ literature.

\subsection{Jet velocity}

Since water is considered as incompressible in the developed numerical model, the theoretical reference velocity of the formed water jet can be calculated by the Bernoulli's equation. Applying an upstream pressure $p_{\text {up }}$ of $200 \mathrm{MPa}$ and a water density $\rho_{\mathrm{w}}$ of $998.2 \mathrm{~kg} / \mathrm{m}^{3}$, it is possible to calculate $v_{\text {th }}$ as:

$$
v_{\text {th }}=\sqrt{\frac{2 p_{\text {up }}}{\rho_{\mathrm{w}}}}=633 \mathrm{~m} / \mathrm{s}
$$

Referring to Figure 13, the numerical model gives a simulated velocity $v_{\text {sim }}$ of $634 \mathrm{~m} / \mathrm{s}$. The percentage error is around $0.16 \%$, which means that the two values are in perfect accordance.
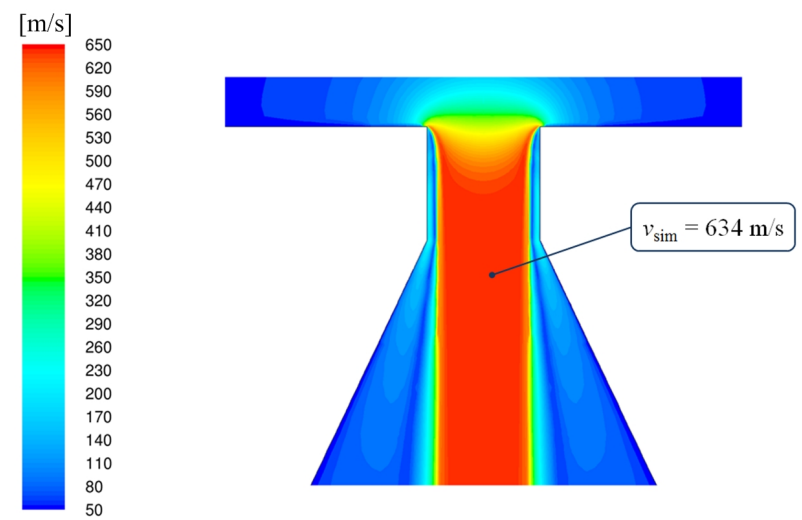

Figure 13: Velocity contours $(\mathrm{m} / \mathrm{s})$ in the capillary region.

Furthermore, as mentioned above, the functionality of the modified orifice has been tested by comparing its coefficient of velocity $C_{\mathrm{v}}$ with the values available in literature for standard 
orifices in order to guarantee that the proposed modification does not affect the orifice performance in terms of real water jet velocity.

For the orifice $C_{\mathrm{v}}$ calculation, it is necessary to evaluate the isoentropic velocity $v_{1 \mathrm{~s}}$ and the real velocity $v_{1}$.

Velocity $v_{1 \mathrm{~s}}$ can be calculated using the following expression proposed by Hashish (1989), where the constants $L$ and $c$ are fixed respectively to $300 \mathrm{MPa}$ and 0.1368 :

$$
v_{1 \mathrm{~s}}=\sqrt{\frac{2 L}{\rho_{\mathrm{w}}(1-c)}\left[\left(1+\frac{p_{\mathrm{up}}}{L}\right)^{1-c}-1\right]}=621 \mathrm{~m} / \mathrm{s}
$$

The real jet velocity $v_{1}$ has been measured by means of a LDV measurement system developed by Annoni et al. (2008b), whose design features and configuration have been specifically optimized for this purpose.

The LDV velocity measurement is based on the scattering frequency of the jet droplets passing through a pattern of light fringes. The fringes are created by the interference between two laser beams intersecting at the orifice exit.

Referring to Figure 14, the optical signal coming from the jet is captured with a high frequency photodiode before being analyzed in the frequency domain by means of an oscilloscope and a custom $\mathrm{LabVIEW}^{\circledR}$ program.

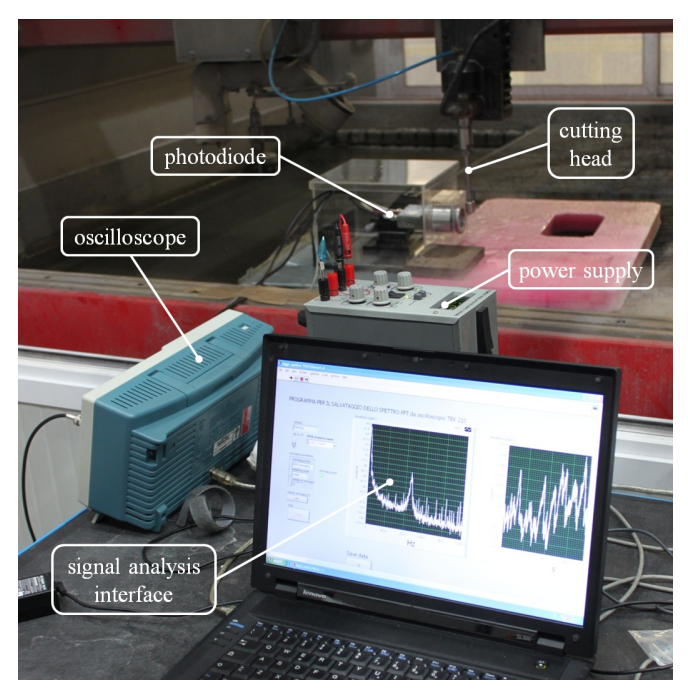

Figure 14: LDV water jet velocity measurement system.

Within his work on the presented system, Malmassari (2012) obtained a mean value for the scattering frequency $f_{\text {peak }}$ of 10.1 MHz (see Figure 15); the upstream working pressure $p_{\text {up }}$ was set to $200 \mathrm{MPa}$ and has been continuously controlled during all the measurement tests. The relation between this value and the real jet velocity is given by the following equation:

$$
v_{1}=\delta f_{\text {peak }}=611 \mathrm{~m} / \mathrm{s}
$$

being the experimentally measured distance between two adjacent light fringes $\delta$ equal to $60.5 \mu \mathrm{m}$.

Finally, the $C_{\mathrm{v}}$ value can be calculated as:

$$
C_{\mathrm{v}}=\frac{v_{1}}{v_{1 \mathrm{~s}}}=0.98
$$

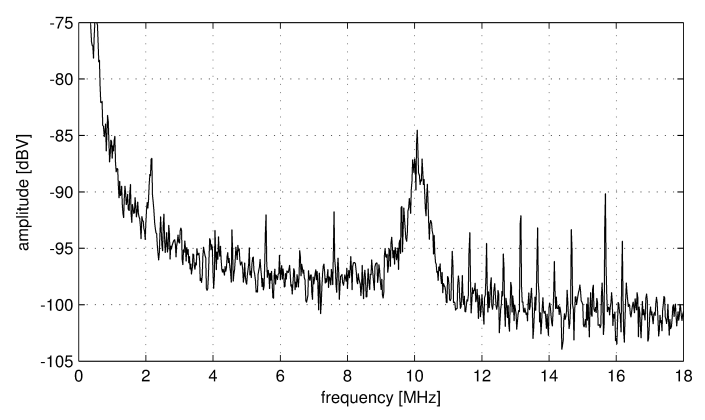

Figure 15: FFT of the optical signal acquired by the LDV measurement system.

which is in accordance with the referenced values about sharpedged orifices presented by Annoni et al. (2008a).

It can be stated then that the proposed orifice modification does not affect the orifice performance in terms of water jet velocity.

\subsection{Coefficient of contraction}

The coefficient of contraction $C_{\mathrm{c}}$ is defined as the area of the contracted liquid jet over the total cross-sectional area of the orifice capillary.

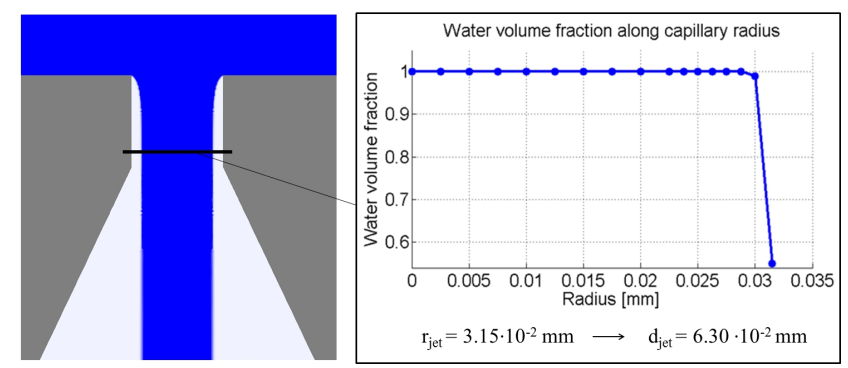

Figure 16: Water volume fraction along the capillary radius extrapolated from the numerical model.

Analyzing the contours plot of different phases volume fractions (Figure 16), it is possible to get the actual section of the formed water jet and so derive the coefficient of contraction $C_{\mathrm{c}, \mathrm{sim}}$. Using a $d_{0}$ value of $0.08 \mathrm{~mm}$ and obtaining the $d_{\mathrm{jet}}$ from the simulation results as reported in Figure $16, C_{\mathrm{c}, \text { sim }}$ can be calculated as:

$$
C_{\mathrm{c}, \operatorname{sim}}=\frac{A_{\mathrm{jet}}}{A_{0}}=\frac{d_{\mathrm{jet}}^{2}}{d_{0}^{2}}=0.62
$$

The coefficient of contraction $C_{\mathrm{c}, \text { th }}$ can be derived theoretically from the fitting equation proposed by Nurick (1976):

$$
C_{\mathrm{c}, \mathrm{th}}=\sqrt{\left(\frac{1}{{C_{\mathrm{ct}}}^{2}}-11.4 \frac{r}{d_{0}}\right)^{-1}}
$$

where $C_{\text {ct }}$ is a theoretical constant equal to 0.611 , coming from potential flow analysis of ideal flipped jets.

In case of ideal sharp edged orifice $(r \rightarrow 0)$ such the one modeled in the present simulations, Eq. 6 gives a $C_{\mathrm{c}, \text { th }}$ value equal to the Nurick's constant $C_{\mathrm{ct}}$ as summarized also by Lienhard (1984). This value is consistent with the value found numerically in Eq. 5 being the difference around $1.5 \%$. 


\subsection{Pressure inside the orifice}

As mentioned in Section 5.2, the radial hole in the orifice tube can be used to acquire the pressure signal very close to the capillary region during machining operations. This chance is really interesting for the experimental validation of the CFD model pressure field. In order to correctly simulate the system configuration presented in Section 5.2, where the radial hole air inlet is closed by the presence of the pressure transducer (Figure 12), a wall boundary condition is applied to the air pressure inlet in the numerical model.

Applying a $p_{\text {up }}$ pressure of $200 \mathrm{MPa}$, the simulated air pressure inside the radial hole is $87200 \mathrm{~Pa}$ (see Figure 17), which is lower than the atmospheric value, due to the Venturi effect caused by the high jet velocity inside the orifice tube.
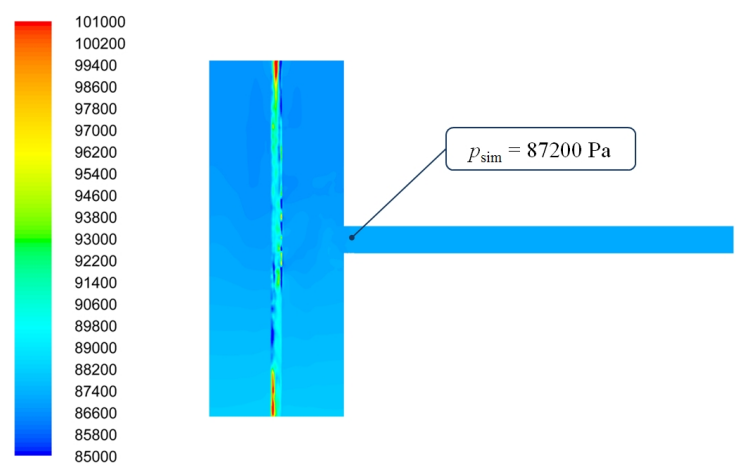

Figure 17: Pressure contours $(\mathrm{Pa})$ in the radial hole region.

Pressure acquisitions have been performed by means of a Valcom ${ }^{\circledR} 27 \mathrm{~A}$ ceramic pressure transducer.

As shown in Figure 18, the pressure level inside the orifice rapidly decreases after the jet is switched on and goes back to the atmospheric value immediately after the switching off.

The operating pressure $p_{\text {up }}$ during the test has been fixed and controlled at $200 \mathrm{MPa}$ as reported by Malmassari (2012), while the average pressure value inside the orifice tube has been calculated as:

$$
p_{\text {meas }}=91300 \pm 500 \mathrm{~Pa}
$$

Deviations between simulated and measured pressures can be due to the fact that air is considered as incompressible in the numerical model.

Anyway, the percentage error between the measured pressure value $p_{\text {meas }}$ and the simulated pressure $p_{\text {sim }}$ is around $4.5 \%$, showing a good numerical model pressure field agreement with reality.

\section{Preliminary cutting tests}

The performances of the developed AAPWJ system and the effects of the jet stability and structure on the cutting quality have been tested on some real case studies, as presented below.

\subsection{AAPWJ cutting of Evazote ${ }^{\circledR}$ foam}

Evazote $^{\circledR}$ is a closed cell cross-linked ethylene copolymer foam with an average density of $50 \mathrm{~kg} / \mathrm{m}^{3}$. Although it is a

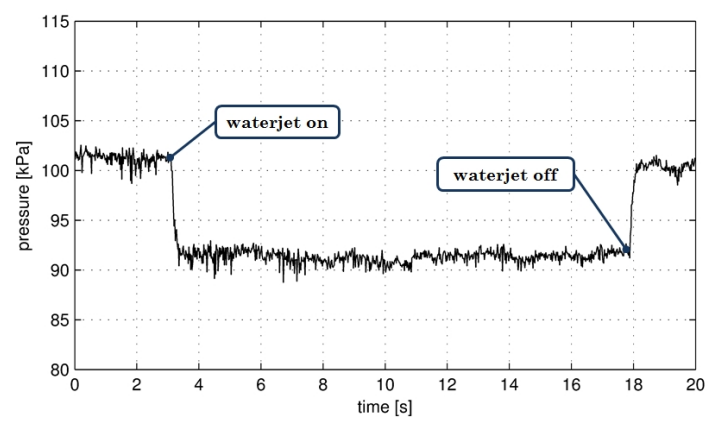

Figure 18: Pressure signal acquired in the orifice radial hole region.

soft material, experience shows that its particular structure often gives problems when cut with a very coherent jet (like the one usually produced by the standard PWJ orifices) especially on thick layers. In fact, the cut leaves some material bridges between the two sides of the kerf in these conditions, making the extraction of the machined parts difficult and worsening the kerf quality. Some trial tests have been made on $15 \mathrm{~mm}$ thick Evazote $^{\circledR}$ sheets with the AAPWJ system, using $200 \mathrm{MPa}$ as upstream water pressure and an orifice diameter of $0.08 \mathrm{~mm}$.

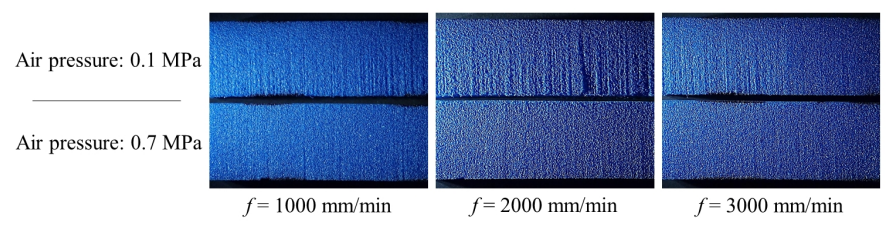

Figure 19: AAPWJ cutting of Evazote with various combinations of air pressure and feed rate $(f)$.

Figure 19 shows a comparison of results obtained with two different air inlet pressures at different feed rates:

0.1 MPa air pressure: this condition refers to a cut with a coherent jet. Evident striations are present and also irregularities and defects can be detected, possibly due to jet instabilities during the machining operations. The kerf surface has the appearance as the material is torn off and burrs are present on the bottom edge. This case represents the actual industrial state of the art.

0.7 MPa air pressure: this condition produces an higher divergence and a less coherent jet structure. The improvement in terms of kerf quality is evident: less striations take place, the surface has a smoother and regular appearance and no burrs are present at the bottom edge. Moreover, results seem feed rate independent, at least within the tested range. The cutting efficiency is effectively enhanced in these conditions.

These cutting tests have been carried out in cooperation with Vito Rimoldi S.r.l., a company involved in the rubber foam gasket manufacturing which appreciated the increased performance of the AAPWJ system comparing to standard PWJ in terms of quality and productivity. 


\subsection{AAPWJ cutting of fabrics}

Cutting of fabrics, or in general materials with a web structure, has always been challenging for WJ technology since the wires forming the plies move apart when the jet hits them during machining operations not allowing a complete separation. A possible but not always effective solution is to reduce the feed rate and use bigger orifice diameters with the main drawbacks of using higher flow rates and so higher power.

Some trial tests have been made on a cotton fabric with the AAPWJ system, using $200 \mathrm{MPa}$ as upstream water pressure, an orifice diameter of $0.08 \mathrm{~mm}$ and the feed rate fixed at $1000 \mathrm{~mm} / \mathrm{min}$. Two different air inlet pressures have been tested $(0.1$ and $0.7 \mathrm{MPa})$ and the cuts have been finally qualitatively compared with a standard scissors cut.

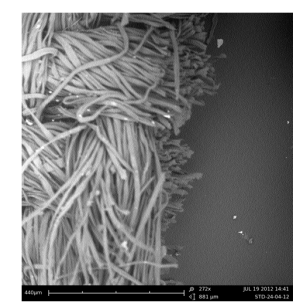

Scissors

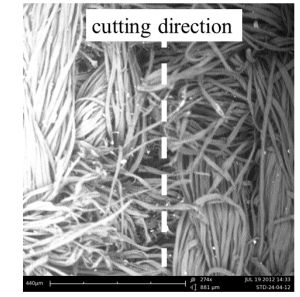

AAPWJ $-0.1 \mathrm{MPa}$

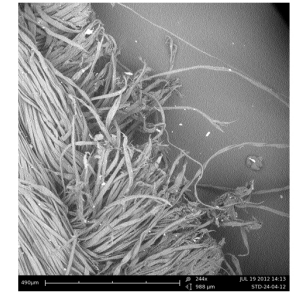

AAPWJ $-0.7 \mathrm{MPa}$
Figure 20: Cutting of a cotton fabric. Comparison between scissors and AAPWJ at various air inlet pressures at a feed rate $f=1000 \mathrm{~mm} / \mathrm{min}$.

Figure 20 shows the test results: the cut made at $0.1 \mathrm{MPa}$ air pressure, which still produces a coherent jet, leaves the two edges undetached as a proof of the abovementioned troubles, while cutting with a less coherent jet, such as the one obtained blowing air at $0.7 \mathrm{MPa}$, produces a clear cut. The scissors cut is obviously the sharpest, but the results obtained with the AAPWJ blowing air at $0.1 \mathrm{MPa}$ seem comparable. In this latter case, the particular structure of the jet dramatically enhances the machinability of such a material even if using a small diameter orifice and relatively high feed rates.

\section{Conclusions}

This paper reports the proof of concept of an innovative Air Assisted Pure Water Jet (AAPWJ) cutting system able to guarantee the optimal working conditions through a controlled air intake inside a PWJ orifice.

The proposed solution has been proved to be viable and gives promising results in terms of both external disturbances reduction and active control on the cutting process. As a matter of fact, this could open the way to new possible high performance PWJ applications.

The new cutting head has been first studied in terms of air flows inside the orifice tube by means of CFD simulations: results indicate how the compressed air injection in the orifice tube is useful to protect the orifice capillary from disturbances and enhance the jet stability. Moreover, it acts on the jet structure as a mean to control its coherence.

CFD simulations have been validated by means of jet velocity and pressure acquisitions at the air inlet, while the effectiveness of the AAPWJ cutting system has been proved by water jet structure observation in air and by real cutting experiments, which demonstrate how the compressed air injection improves the jet performance on the tested target materials.

Finally, further developments will include the air pressure acquisition inside the orifice tube for process monitoring purposes, experimental campaigns aimed at a quantitative evaluation of the cutting quality improvement and the transfer of this solution to AWJ too for a comprehensive enhancement of the water jet technology as a whole.

\section{Acknowledgments}

This study has been carried out in the frame of a collaboration between Dipartimento di Meccanica and Dipartimento di Energia of Politecnico di Milano. The authors are grateful to both the institutions, to Professor Inzoli and to Vito Rimoldi S.r.l. for their support.

\section{Nomenclature and abbreviations}

\begin{tabular}{|c|c|c|}
\hline Symbol & Unit & Definition \\
\hline$A_{0}$ & $\mathrm{~mm}^{2}$ & nominal capillary section area \\
\hline$A_{\text {jet }}$ & $\mathrm{mm}^{2}$ & jet section area \\
\hline$C_{\mathrm{c}}$ & - & coefficient of contraction \\
\hline$C_{\mathrm{c}, \mathrm{sim}}$ & - & numerical coefficient of contraction \\
\hline$C_{\mathrm{c}, \mathrm{th}}$ & - & theoretical coefficient of contraction \\
\hline$C_{\mathrm{ct}}$ & - & Nurick's fit constant \\
\hline$C_{\mathrm{v}}$ & - & coefficient of velocity \\
\hline$d_{0}$ & $\mathrm{~mm}$ & capillary diameter \\
\hline$f$ & $\mathrm{~mm} / \mathrm{min}$ & feed rate \\
\hline$f_{\text {peak }}$ & $\mathrm{MHz}$ & LDV scattering frequency \\
\hline$p_{\text {air }}$ & $\mathrm{MPa}$ & air inlet pressure \\
\hline$p_{\text {down }}$ & $\mathrm{kPa}$ & water downstream pressure \\
\hline$p_{\text {meas }}$ & $\mathrm{kPa}$ & pressure measured inside the orifice \\
\hline$p_{\text {sim }}$ & $\mathrm{kPa}$ & numerical pressure inside the orifice \\
\hline$p_{\text {up }}$ & $\mathrm{MPa}$ & water upstream pressure \\
\hline$r$ & $\mu \mathrm{m}$ & capillary edge radius \\
\hline $\operatorname{Re}$ & - & Reynolds number \\
\hline$v_{1}$ & $\mathrm{~m} / \mathrm{s}$ & real jet velocity \\
\hline$v_{1 \mathrm{~s}}$ & $\mathrm{~m} / \mathrm{s}$ & isoentropic jet velocity \\
\hline$v_{\text {sim }}$ & $\mathrm{m} / \mathrm{s}$ & simulated jet velocity \\
\hline$v_{\mathrm{th}}$ & $\mathrm{m} / \mathrm{s}$ & theoretical jet velocity \\
\hline$\delta$ & $\mu \mathrm{m}$ & LDV fringe distance \\
\hline$\rho_{\mathrm{w}}$ & $\mathrm{kg} / \mathrm{m}^{3}$ & water density \\
\hline
\end{tabular}

\section{References}

Anantharamaiah, N., Vahedi Tafreshi, H., Pourdeyhimi, B., 2006. A study on flow through hydroentangling nozzles and their degradation. Chemical Engineering Science vol. 61, pp. 4582-4594.

Annoni, M., Cristaldi, L., Faifer, M., Norgia, M., 2008a. Orifice coefficients evaluation for water jet applications. Proceedings of the 16th IMEKO TC4 Symposium, Firenze .

Annoni, M., Cristaldi, L., Norgia, M., Svelto, C., 2008b. Measurement of water jet velocity distribution using laser velocimetry. IEEE Transactions on Instrumentation and Measurement vol. 57, pp. 1524-1528. 


\section{Acronym Definition}

$\begin{array}{ll}\text { AAPWJ } & \text { Air Assisted Pure Water Jet } \\ \text { AWJ } & \text { Abrasive Water Jet } \\ \text { BC } & \text { Boundary Condition } \\ \text { CFD } & \text { Computational Fluid Dynamics } \\ \text { EDM } & \text { Electro Discharge Machining } \\ \text { LDV } & \text { Laser Doppler Velocimetry } \\ \text { PWJ } & \text { Pure Water Jet } \\ \text { VOF } & \text { Volume Of Fluid } \\ \text { WJ } & \text { Water Jet }\end{array}$

Annoni, M., Monno, M., 2006. Effects of diamond orifice geometry on water jet cutting performance. Proceedings of the 18th BHR International Conference on Water Jetting, Gdansk (Poland) pp. 293-308.

Ansys, 2009a. Fluent 12.0 Theory Guide. Ansys Inc., Canonsburg, USA.

Ansys, 2009b. Fluent 12.0 User's Guide. Ansys Inc., Canonsburg, USA.

Arleo, F., 2010. Numerical simulation of a pure water jet inside an orifice: jet stability and effects of droplets collisions. Politecnico di Milano. Master thesis.

Arleo, F., Annoni, M., Basha, A., Monno, M., Inzoli, F., 2011. Analysis of the effects of droplets collisions on the stability of a pure water jet by means of 3D numerical simulations. Proceedings of the 10th AITeM Conference, Napoli .

Basha, A., Annoni, M., Monno, M., Inzoli, F., in press. Investigation of the hydrodynamic characteristics of AWJ cutting head. International Journal of Machining and Machinability of Materials .

FirstTenAngstroms, 2003. Contact angle and surface energy measurements on steel. Application notes. First Ten Ångstroms. Portsmouth, USA.

Hashish, M., 05 Apr 2005. Method for fluid jet formation. Patent US 6875084 B2. Flow International Corporation. Kent WA (US).

Hashish, M., 1989. Pressure effects in abrasive waterjet (AWJ) machining. Journal of Engineering Materials and Technology vol. 111, pp. 221-228.

Hashish, M., 24 Dec 2009. Vented cutting head body for abrasive jet system. Patent US 2009/0318064 A1. Flow International Corporation. Kent WA (US).

Jou, M., 2000. Analysis of the stability of water-jet cutting with linear theory. Journal of Materials Processing Technology vol. 104, pp. 17-20.

Lefebvre, A.H., 1989. Atomization and sprays. Hemisphere Publishing Corporation, New York, USA.

Lichtarowicz, A., Duggins, R.K., Markland, E., 1965. Discharge coefficients for incompressible non-cavitating flow through long orifices. Mechanical Engineering Science vol. 7(2), pp. 210-219.

Lienhard, J.H., 1984. Velocity coefficients for free jets from sharp-edged orifices. Journal of Fluid Engineering vol. 106, pp.13-17.

Lin, S.P., Reitz, R.D., 1998. Drop and spray formation from a liquid jet. Annual Review of Fluid Mechanics vol. 30, pp. 85-105.

Liu, H., Wang, J., Kelson, N., Brown, R., 2004. A study of abrasive waterjet characteristics by CFD simulation. Journal of Materials Processing Technology vol. 153-154, pp. 488-493.

Malmassari, C., 2012. Analisi numerica e sperimentale del processo di efflusso attraverso un ugello innovativo per applicazioni pure water jet. Politecnico di Milano. Master thesis.

Monno, M., Annoni, M., Ravasio, C., 2007. Water jet: a flexible technology. Polipress, Milano.

Nurick, W.H., 1976. Orifice cavitation and its effects on spray mixing. Journal of Fluid Engineering vol. 98, pp.681-687.

Ohnesorge, W.V., 1936. Die bildung von tropfen an dusen und die auflosung flussiger strahlen. Zeitschrift fur Angewandte Mathematik und Mechanik vol. 16, pp. 355-358.

Prisco, U., D'Onofrio, M., 2009. Three-Dimensional CFD Simulation of TwoPhase Flow Inside the Abrasive Water Jet Cutting Head. International journal for computational methods in engineering science and mechanics vol.9, pp. 300-319.

Schweitzer, P.H., 1937. Mechanism of disintegration of liquid jets. Journal of
Applied Physics vol. 8, pp. 513-521.

Vahedi Tafreshi, H., Pourdeyhimi, B., 2003. The effects of nozzle geometry on waterjet breakup at high Reynolds numbers. Experiments in Fluids vol. 35, pp. $364-371$

Wang, R., Wang, M., 2010. A two-fluid model of abrasive waterjet. Journal of Materials Processing Technology vol. 210, pp. 190-196. 